\title{
A pesquisa em educação ambiental em diferentes áreas do conhecimento - algumas reflexões ${ }^{1}$
}

Carlos Saito $^{2}$

Resumo: Debater sobre a pesquisa em educação ambiental (EA) em diferentes áreas do conhecimento implica tratar das interfaces de áreas do conhecimento, e não falar das áreas do conhecimento propriamente ditas. Além disso, essas interfaces devem ser analisadas à luz dos princípios e objetivos da Política Nacional de Educação Ambiental (Lei no 9795/1999). Para tanto, alguns exemplos de pesquisas são apresentados agrupados por temas: abordagem dialógicoproblematizadora e conflitos socioambientais; mediação científico-tecnológica; o mito da democracia e participação; escalas geográficas; Teoria Geral de Sistemas e a espiral lewiniana; planejamento curricular, projetos coletivos e a relevância da pesquisa; as instalações físicas da escola para a EA; conhecimento e valores. Nessas experiências, discute-se a possibilidade de construção ou não de valores sociais, conhecimentos, habilidades, atitudes e competências que permeiam as práticas de EA e devem, portanto, constituir foco de atenção das pesquisas em EA.

Palavras-chave: Educação ambiental. Fundamentos teórico-metodológicos. Areas do conhecimento.

\section{Research on environmental education in different areas of knowledge - some reflections}

Abstract: To discuss research on environmental education (EE) in different areas of knowledge leads to analyzing the interfaces among the areas of knowledge, not the areas of knowledge themselves. In addition, those interfaces should be considered in the light of the principles and objectives of the National Environmental Education Policy (Law No. 9795/1999). In order to do so, some examples of research are presented grouped by themes: dialogical problem-solving approach and socioenvironmental conflicts; scientific and technological mediation; the myth of democracy and participation; geographic scales; General Systems Theory and Lewin's action-research spiral; curriculum planning, collective projects and the relevance of research; the impact of the physical building of the

\footnotetext{
${ }^{1}$ Texto produzido a partir das discussões conduzidas na mesa-redonda "A pesquisa em Educação Ambiental em diferentes áreas do conhecimento", no VI Encontro de Pesquisa em Educação Ambiental (EPEA), Ribeirão Preto-SP, de 04 a 07 de setembro de 2011.

2 Biólogo e Analista de Sistemas, Mestre em Educação e Doutor em Geografia Universidade de Brasília ,Brasília, Brasil, carlos.h.saito@hotmail.com.
} 
school for EE; knowledge and values. In those educational experiences, we discuss whether it is possible or not to promote the construction of social values, knowledge, skills, attitudes and competences that constitute EE practice and therefore should be the focus of research on EE.

Keywords: Environmental Education. Theoretical and methodological foundations. Areas of knowledge.

\section{La investigación en educación ambiental en diferentes áreas del conocimiento - algunas reflexiones}

Resumen: Debatir sobre la investigación en educación ambiental (EA) en diferentes áreas del conocimiento implica tratar de las interfaces de áreas del conocimiento, y no hablar de las áreas del conocimiento propiamente dichas. Además, estas interfaces deben analizarse a la luz de los principios y objetivos de la Política Nacional de Educación Ambiental (Ley no 9795/1999). Para esto, algunos ejemplos de investigaciones se presentan agrupados por temas: abordaje dialógicoproblematizador y conflictos socioambientales; mediación científico-tecnológica; el mito de la democracia y participación; escalas geográficas; Teoría General de Sistemas y la espiral lewiniana; planeamiento curricular, proyectos colectivos y la relevancia de la investigación; las instalaciones físicas de la escuela para la EA; conocimiento y valores. En esas experiencias, se discute la posibilidad de construcción o no de valores sociales, conocimientos, habilidades, actitudes y competencias que permean las prácticas de EA y deben, por tanto, constituir el foco de atención de las investigaciones en EA.

Palabras clave: Educación ambiental. Fundamentos teórico-metodológicos. Áreas del conocimiento.

\section{Introdução}

A educação ambiental (EA) é vista como portadora de grandes responsabilidades no que tange à construção do futuro da humanidade, na perspectiva de uma sociedade sustentável e em harmonia com o meio ambiente. Seu desenvolvimento e implementação, apesar dessa expectativa depositada, sofrem enormes dificuldades, sobretudo pelo histórico de constituição das áreas de conhecimento de forma disciplinar e, por conseguinte, pela formação dos pesquisadores e docentes em todos os níveis do sistema educacional.

Portanto, refletir sobre a pesquisa em educação ambiental em diferentes áreas do conhecimento pode nos colocar na bifurcação de dois caminhos: discutir sobre as áreas do conhecimento que podem estar envolvidas numa pesquisa em EA ou tratar das interfaces de áreas do conhecimento, (e não falar das áreas do conhecimento propriamente ditas).

No presente trabalho, procura-se explorar o segundo caminho, tratando-se das interfaces e dos conhecimentos associados a essa relação, a partir de alguns 
estudos de caso. Além disso, essas interfaces devem ser analisadas à luz dos princípios e objetivos da EA, que no nosso contexto defende-se que deve se basear na vigente Política Nacional de Educação Ambiental (Lei no 9795/1999), de modo que com base nesses princípios e objetivos se possam também analisar as articulações entre o relato descritivo e os avanços no campo teóricometodológico da pesquisa em educação ambiental. Finalmente, nessas experiências, discute-se a construção ou não de valores sociais, conhecimentos, habilidades, atitudes e competências que permeiam as práticas de EA e devem, portanto, constituir foco de atenção das pesquisas em EA.

\section{A Política Nacional de Educação Ambiental}

Apresentam-se a seguir alguns princípios e objetivos da Política Nacional de Educação Ambiental (respectivamente artigos 4o e 5o) buscando relacioná-los entre si de tal modo que para cada princípio listado aponte-se um objetivo correlato (Tabela 1).

Estes princípios e objetivos foram destacados para subsidiar a discussão dos estudos de caso que são descritos a seguir e auxiliar o entendimento de como essas pesquisas se desdobram tanto em produtos do ponto de vista descritivo dos casos quanto em produtos do ponto de vista do aprofundamento teóricometodológico na educação ambiental, como interface de áreas do conhecimento. Esse esforço de articulação e apresentação da articulação entre o caráter descritivo e o caráter de aprofundamento teórico-metodológico deve-se à constante preocupação de avançar na pesquisa ultrapassando o mero relato descritivo, crítica muitas vezes repetida nos Encontros de Pesquisa em Educação Ambiental.

\begin{tabular}{|c|c|}
\hline Princípio (Artigo 4을 & Objetivo (Artigo 5을 \\
\hline $\begin{array}{l}\text { II- a concepção do meio ambiente em sua } \\
\text { totalidade, considerando a interdependência } \\
\text { entre o meio natural, o sócio-econômico [sic] } \\
\text { e o cultural, sob o enfoque da } \\
\text { sustentabilidade; }\end{array}$ & $\begin{array}{l}\text { I- o desenvolvimento de uma } \\
\text { compreensão integrada do meio } \\
\text { ambiente em suas múltiplas e } \\
\text { complexas relações, envolvendo } \\
\text { aspectos ecológicos, psicológicos, } \\
\text { legais, políticos, sociais, econômicos, } \\
\text { científicos, culturais e éticos; }\end{array}$ \\
\hline $\begin{array}{l}\text { VII- a abordagem articulada das questões } \\
\text { ambientais locais, regionais, nacionais e } \\
\text { globais; }\end{array}$ & $\begin{array}{l}\text { V- o estímulo à cooperação entre as } \\
\text { diversas regiões do País, em níveis } \\
\text { micro e macrorregionais, com vistas à } \\
\text { construção de uma sociedade } \\
\text { ambientalmente equilibrada, fundada } \\
\text { nos princípios da liberdade, igualdade, }\end{array}$ \\
\hline
\end{tabular}




\begin{tabular}{|l|l|l|} 
& & $\begin{array}{l}\text { solidariedade, democracia, justiça } \\
\text { social, responsabilidade e } \\
\text { sustentabilidade; }\end{array}$ \\
\hline $\begin{array}{l}\text { IV- a vinculação entre a ética, a educação, o } \\
\text { trabalho e as práticas sociais; }\end{array}$ & $\begin{array}{l}\text { III- o estímulo e o fortalecimento de } \\
\text { uma consciência crítica sobre a } \\
\text { problemática ambiental e social; }\end{array}$ \\
\hline $\begin{array}{l}\text { VI- a permanente avaliação crítica do } \\
\text { processo educativo; }\end{array}$ & $\begin{array}{l}\text { VI- o fomento e o fortalecimento da } \\
\text { integração com a ciência e a } \\
\text { tecnologia; }\end{array}$ \\
\hline $\begin{array}{l}\text { VIII- o reconhecimento e o respeito à } \\
\text { pluralidade e à diversidade individual e e } \\
\text { cultural. }\end{array}$ & $\begin{array}{l}\text { VII- o fortalecimento da cidadania, } \\
\text { autodeterminação dos povos e e } \\
\text { solidariedade como fundamentos para } \\
\text { o futuro da humanidade. }\end{array}$ \\
\hline
\end{tabular}

Portanto, de forma a se poder debater a articulação entre o relato descritivo e os avanços no campo teórico-metodológico da pesquisa em educação ambiental, alguns exemplos de pesquisas realizadas (estudos de caso) em diferentes interfaces (e não áreas) do conhecimento são apresentados, organizados na forma de temas para guiar a reflexão: abordagem dialógicoproblematizadora e conflitos socioambientais; mediação científico-tecnológica; o mito da democracia e participação; escalas geográficas; Teoria Geral de Sistemas e a espiral lewiniana; planejamento curricular, projetos coletivos e a relevância da pesquisa; as instalações físicas da escola para a EA; conhecimento e valores.

Cada um dos estudos de caso agrupados nos temas se encontram descritos a seguir com brevidade, tendo em conta que o objetivo do presente trabalho não é a discussão dos casos em si, o que pode ser obtido nos trabalhos que os relatam e que se encontram publicados, mas apresentar um panorama desses estudos de caso e suas articulações com o aprofundamento teórico-metodológico e a explicitação das interfaces de áreas do conhecimento envolvidas na pesquisa/intervenção.

\section{Os temas que agrupam os estudos de caso}

Por uma questão didática, o texto apresenta-se em blocos com estruturas propositalmente repetitivas, com a listagem dos estudos de caso, uma breve descrição de cada um deles e uma explicação de como a produção descritiva e a produção teórico-metodológica se articulam, de como esses estudos de caso se 
situam na interface das diferentes áreas do conhecimento e de qual é o vínculo dessas reflexões com os objetivos da Política Nacional de Educação Ambiental.

\section{Abordagem dialógico-problematizadora e conflitos socioambientais}

No que se refere ao tema abordagem dialógico-problematizadora e conflitos socioambientais, apresentam-se três estudos de caso que podem ser ilustrativos das pesquisas e intervenções em educação ambiental e que se encontram interligados por meio de um processo contínuo de elaboração e reelaboração teóricometodológica: 1) o emissário submarino na Barra da Tijuca, Rio de Janeiro-RJ, em meados da década de 1980; 2) o material didático Probio-EA, produzido para o Ministério do Meio Ambiente em 2006; 3) a campanha para a redução do uso de copos descartáveis no Restaurante Universitário da Universidade de Brasília no início dos anos 2000.

O primeiro caso, descrito em Saito (1999), trata da luta popular das Associações de Moradores de diversos bairros do Rio de Janeiro-RJ para impedir a construção do emissário submarino na Barra da Tijuca, nos termos do projeto originalmente proposto pelo governo do estado, e de como isso serviu de ponto de partida para um trabalho educacional em escola de ensino fundamental na comunidade do Rio das Pedras, em Jacarepaguá, no ano de 1986, cuja reflexão sobre a experiência resultou na publicação citada anteriormente. A partir da problematização do projeto de construção do emissário submarino, pôde o professor de ciências das turmas de $5^{\text {a }}$ série desenvolver o conteúdo programático previsto para essa série escolar pelo currículo oficial (conceitos associados a água, ar e solo, ciclagem de nutrientes, ecossistema, saneamento básico e saúde pública), além de contribuir para a mobilização dos alunos e sua participação tanto na Associação de Moradores de sua comunidade como na campanha contra o emissário submarino, que tinha como lema "Cocô na praia, não!". O trabalho ainda teve como desdobramento a participação dos alunos na luta da sua Associação de Moradores pelo saneamento básico na sua comunidade, o que remeteu a uma discussão sobre o conceito freireano de tema gerador (FREIRE, 1988) e o conceito de dialogicidade, que não poderia ser confundido com amabilidade ou sondagem sobre os assuntos de interesse dos alunos, sob o risco de filiar-se a uma moldura conceitual neoliberal que distorce o compromisso teórico original de Freire, conforme Saito e Santiago (1998). Defendeu-se um entendimento de que o diálogo se daria no contexto de um processo histórico em que os dialogantes não seriam as pessoas individuais (a escala de indivíduo muito valorizada no pensamento liberal), mas os sujeitos históricos lutando por reivindicações do movimento social organizado. Ou seja, há uma relação fecunda entre a prática e a teoria, uma alimentação mútua, o que reflete na formação do próprio pesquisador/educador ambiental, que não precisa, necessariamente, ocorrer concomitantemente num intervalo restrito e 
curto, mas ao longo de uma trajetória de atuação e formação. Pode-se ainda apontar uma articulação entre essa experiência e um esforço teórico em torno dos desafios da Política Nacional de Educação Ambiental para a construção de uma cidadania ativa e crítica que, além de desvelar as relações de dominação (opressão social) em nossa sociedade, indica a necessidade de remeter-se à prática de uma ação transformadora intencional (SAITO, 2002).

O segundo caso, cujas bases descritivas e também conceituais encontram-se principalmente em Saito et al. (2008), trata do material didático Probio-Educação Ambiental (Probio-EA), composto de pares de portfólios, livro do professor e jogo educativo de tabuleiro e produzido para o Ministério do Meio Ambiente em 2006, encontrando-se disponível em http://www.ecoa.unb.br/probioea/. Nesse caso, mantendo-se o mesmo referencial anterior (Paulo Freire), avançou-se para o desenvolvimento de uma estratégia de problematização em educação ambiental partindo-se de conflitos socioambientais. A presença desse novo componente permitiu pensar num par de portfólios situações-problema (conflitos socioambientais) e na resolução dessas situações (ação positiva), articuladas entre si, o que levou alguns anos mais tarde à realização de uma mesa-redonda específica sobre o tema (MR10 - Conflitos Socioambientais, Educação Ambiental e Participação Social na Gestão Ambiental) durante o V Encontro Nacional da Associação Nacional de Pesquisa e Pós-Graduação em Ambiente e Sociedade (V ENANPPAS), realizado em Florianópolis-SC, em outubro de 2010. Essa mesa-redonda, que contou com a participação de pesquisadores externos e alheios ao processo de produção do material didático Probio-EA, foi gravada, transcrita e reformatada para fins de publicação e produziu um aprofundamento teórico-metodológico em torno do uso de conflitos socioambientais como ponto de partida para ações de educação ambiental (SAITO et al., 2011).

O terceiro caso, descrito em Viegas et al. (2007), tratou das ações de conscientização dos usuários do Restaurante Universitário da Universidade de Brasília, visando reduzir o desperdício de copos descartáveis, uma vez que foi constatado que muitos usuários pegavam mais de um copo plástico na mesma refeição para beber o suco que era servido. Nesse trabalho, buscou-se resgatar o processo dialógico-problematizador em que os usuários eram "provocados" por histórias em quadrinhos disponibilizadas para leitura nas mesas de refeição, protegidas pelo plástico que recobre as mesas. Essas histórias representavam o produto de um processo de codificação e convidavam para uma problematização, dando início a uma interação dialógica em meio a um processo de decodificação. A experiência buscou suporte em Paulo Freire para desenvolver uma estratégia dialógico-problematizadora que fizesse emergir a consciência entre os usuários, sem que houvesse uma intervenção prescritiva e unidirecional de comunicação, condenada por Freire (1977). Os pesquisadores/educadores deveriam estar invisíveis ao público, à semelhança do que era feito nos trabalhos empreendidos por Augusto Boal com seu Teatro Invisível (BOAL, 1975). Além disso, todo o 
contexto em que se desenvolveu essa ação e os conflitos instaurados com a direção do restaurante em torno da substituição dos copos descartáveis por canecas portadas individualmente pelos usuários do restaurante permitiram a emergência de um entendimento sobre os pontos centrais de resistência por parte da área de conhecimento da nutrição e da administração de restaurantes: a existência de um paradigma orientador das práticas baseado na necessidade de a administração assumir para si toda a responsabilidade da higienização dos utensílios disponibilizados aos usuários, sob o temor de culpabilização em caso de contaminação, o que poderia ocorrer se os usuários não higienizassem adequadamente suas canecas. Ou seja, aliando-se heteronomia e centralização como oposição à autonomia e descentralização, cultiva-se um modo de olhar de eterna desconfiança em relação ao usuário do restaurante.

Nesses três casos citados, observa-se uma articulação entre teoria e prática, a produção científica tanto de relatos descritivos como de aprofundamento teórico-metodológico resultante dessa articulação teoria-prática, assim como o enquadramento dessa produção na interface de diversas áreas do conhecimento: a educação de modo geral (e dentro dela, mais especificamente, a didática, a psicologia da educação, a sociologia da educação, a filosofia da educação, o currículo e o ensino de ciências) e as áreas de ecologia (e dentro dela a ecologia de ecossistemas, a biogeoquímica, o licenciamento, a gestão de resíduos), a ciência política, a economia, as artes (dentro dela, o desenho, as artes plásticas e o teatro) e a nutrição (dentro dela, a administração de restaurantes e as boas práticas de higienização).

Além disso, essas articulações teoria-prática no âmbito dessa temática estão de acordo com os objetivos da Política Nacional de Educação Ambiental, particularmente no que se refere ao Artigo 5-I, que preconiza o desenvolvimento de uma compreensão integrada do meio ambiente em suas múltiplas e complexas relações, envolvendo aspectos ecológicos, psicológicos, legais, políticos, sociais, econômicos, científicos, culturais e éticos, e ao Artigo 5-III, que trata do estímulo e do fortalecimento de uma consciência crítica sobre a problemática ambiental e social.

\section{Mediação científico-tecnológica}

No que se refere ao tema mediação cientifico-tecnológica, apresentam-se quatro estudos de caso que podem ser ilustrativos das pesquisas e intervenções em educação ambiental e que se encontram interligados por um processo contínuo de elaboração e reelaboração teórico-metodológica: 1) o empoderamento da Comissão Pró-Comitê de Bacia hidrográfica do Alto Rio Maranhão (DF/GO); 2) o material didático Probio-EA, produzido para o Ministério do Meio Ambiente em 2006; 3) o Comitê de Bacia Hidrográfica do Rio Paraguaçu (BA); 4) o caso do menino William Kamkwamba, que "descobriu o vento". 
O primeiro caso, descrito em Berlinck et al. (2003), trata da experiência conduzida pela equipe do Departamento de Ecologia da Universidade de Brasília para promover o empoderamento da Comissão Pró-Comitê de Bacia hidrográfica do Alto Rio Maranhão (DF/GO) a partir de apoio técnico, especialmente no processo de delimitação da área de atuação dessa comissão. $O$ trabalho teve início a partir da constatação da dificuldade dos membros da comissão em definir sua área de atuação, pois estes haviam se preocupado inicial e exclusivamente com a mobilização das comunidades para pensar numa gestão participativa em escala mais ampla do Rio Maranhão, que era o foco das atenções históricas dos seus principais articuladores, sem pensar na delimitação da área de atuação. Quando indagados sobre o assunto, demonstraram surpresa e insegurança. Assim, uma série de reuniões em que se lançou mão de recursos de geoprocessamento e sensoriamento remoto permitiu, em um processo participativo de análise de diferentes cenários e abrangências geográficas, a apreensão de conceitos científicos, como escalas geográficas, pontos cardeais, divisor de águas, bacia de drenagem, hierarquia de rios etc., até que finalmente puderam ser definidos os limites de atuação de forma consensual, optando-se por uma abrangência territorial próxima do primeiro terço do Rio Maranhão (alto curso), com base numa justificativa elaborada por um dos membros da comissão de que poderia sair de casa de manhã cedo, ir até a extremidade da área de atuação para conversar com um proprietário rural e retornar para sua casa no mesmo dia. Ficou assim estabelecido um critério de tamanho de (sub)bacia hidrográfica e área de abrangência de um Comitê de Bacia Hidrográfica para permitir uma real capilarização da mobilização social, critério que foi rejeitado pela tecnocracia da Agência Nacional de Águas.

O segundo caso, que trata do material didático Probio-Educação Ambiental (Probio-EA), já comentado na subseção anterior e cujas bases descritivas e também conceituais encontram-se principalmente em Saito, Bastos e Abegg (2008), tem nos portfólios de ação positiva que abordam a resolução dos conflitos socioambientais a valorização da mediação científico-tecnológica como solução negociada na esfera da conscientização, na perspectiva da justiça social e sustentabilidade socioambiental (Saito et al., 2011). Exemplos são diversos no material, tratando desde como produzir um arroz ecológico integral usando rodízio de parcelas alagadas, plantas nativas fixadoras de nitrogênio e marrecos e a criação de animais para substituir tanto o adubo químico como os herbicidas e pesticidas, passando pelo emprego de um móbile similarmente a uma pipa em formato de gavião de asas abertas para combater a presença de caturritas nas plantações de milho, em substituição ao emprego de iscas envenenadas, até o domínio do conceito de bacia de drenagem a partir do lançamento da hidrografia num mapa para desmistificar a retórica de não prejuízo ao Pantanal por meio da aprovação do projeto de lei que autorizaria a instalação de agroindústrias de canade-açúcar. 
É importante esclarecer que, conforme mencionado, a produção desse material didático foi pautada por um referencial teórico dialógicoproblematizador, voltado para a emancipação e justiça social, cujas bases iniciais foram lançadas anos antes, em Saito $(2001,2002)$, mas foram revistas em Santos et al. (2005), que reconheceu justamente a centralidade da mediação científicotecnológica nesses processos educativos, vindo a complementar e cimentar a triangulação anterior entre a pedagogia dialógico-problematizadora, o empowerment e a pesquisa-ação (investigação-ação). Ressalta-se aqui que a principal inspiração para essa atualização teórica foi encontrada na obra de Bazin (1977).

O terceiro caso trata da análise do componente participação social na estruturação do Comitê de Bacia Hidrográfica do Rio Paraguaçu (BA), apresentado em Pereira e Saito (2010), cujo diagnóstico elucidativo que indicou uma assimetria e desproporcionalidade na representação entre regiões geográficas ou trechos de bacia hidrográfica (alto, médio e baixo curso do rio) só foi possível por meio da aplicação de técnicas de geoprocessamento. Ou seja, um instrumental tecnológico demonstrou ser necessário e decisivo para uma melhor compreensão da dinâmica espacial e parte essencial das estratégias de diálogo com os atores sociais que configurassem uma ação de educação ambiental. Além disso, conforme Pereira e Saito (2010), esse diagnóstico, produzido por uma análise espacial de varredura tanto sobre a representatividade espacial como sobre a localização dos conflitos entre usos de recursos hídricos, permite repensar a estruturação da participação social mediada por critérios técnicos baseados nas demandas, e não apenas como resultado do confronto de forças políticas, como a tradição de oligarquias regionais, consagrando a primazia da racionalidade no exercício das práticas sociais, tal como defendido por Habermas $(1970,1994)$.

O quarto caso é descrito no livro "O menino que descobriu o vento" (KAMKWAMBA; MEALER, 2011), em que William Kamkwamba, vivendo em Malauí, uma das regiões mais pobres da África, aos 13 anos, depois de deixar o sistema educacional formal para auxiliar no sustento da família, encontra num livro da biblioteca local a explicação sobre o funcionamento dos moinhos de vento e constrói, com sucatas, um moinho para permitir que a família tivesse eletricidade e água encanada. Em que pese o espírito curioso e empreendedor, a coragem do jovem rapaz e o autodidatismo que marca o seu aprendizado sobre o funcionamento do moinho, há nisso tudo uma valorização da mediação científico-tecnológica: vivemos num mundo tecnológico, e ele pode ser um instrumento para promover sustentabilidade, gerando melhores condições de vida e renda e minimizando a pressão sobre o meio ambiente. Mais do que isso, trata-se de um exemplo de alfabetização científico-tecnológica, em que desmistificar a caixa preta, ter a coragem de desmontar e montar e tentar entender por dentro o funcionamento da tecnologia, como defendia Bazin (1977), é o que permite transformar sonhos e boas intenções, ainda que ambientalmente comprometidas, em realidade, sem abandonar sua cultura e 
tradição. O feito de William Kamkwamba causou grande impacto e despertou muita curiosidade e admiração que rapidamente correu o mundo. Ele veio a ter seu perfil traçado no $W$ all Street Journal e ser convidado para fazer um discurso no Fórum Econômico Mundial em 2008.

Nos três primeiros casos citados, observa-se novamente um esforço para uma articulação entre teoria e prática, com o desenvolvimento de produção científica tanto de relatos descritivos como de aprofundamento teóricometodológico resultante dessa articulação. O quarto caso, descritivo, corrobora as discussões anteriores e o referencial sobre a importância da mediação científico-tecnológica em processos emancipatórios. Pode-se também reconhecer o enquadramento dessa produção na interface de diversas áreas do conhecimento: a administração (gestão participativa de bacias hidrográficas, resolução de conflitos), o direito (conceito de mediação), as geociências (cartografia temática, geoprocessamento e sensoriamento remoto), a educação de modo geral (e dentro dela, mais especificamente, a didática e o ensino de ciências, com o conceito de alfabetização científico-tecnológica), além das áreas de ecologia (e dentro dela a ecologia de ecossistemas), a ciência política, a economia e até as artes e o desenho industrial (na confecção de maquete para a compreensão do conceito de bacia hidrográfica). No quarto caso, ainda se agregam conhecimentos de engenharia mecânica e elétrica, física e climatologia, além de um rico conhecimento de aspectos socioculturais de uma porção miserável da África.

Além disso, as articulações teoria-prática no âmbito dessa temática estão de acordo com os objetivos da Política Nacional de Educação Ambiental, particularmente no que se refere ao Artigo 5-VI, que trata do fomento e do fortalecimento da integração com a ciência e a tecnologia. O quarto estudo de caso ainda atende ao disposto na Política Nacional de Educação Ambiental no Artigo 4-VIII - o reconhecimento e o respeito à pluralidade e à diversidade individual e cultural - e no Artigo 5-VII - o fortalecimento da cidadania, a autodeterminação dos povos e a solidariedade como fundamentos para o futuro da humanidade.

\section{O mito da democracia e participação}

No que se refere ao tema o mito da democracia e participação, apresenta-se um estudo de caso que pode ser ilustrativo das pesquisas e intervenções em educação ambiental.

Comentado na subseção anterior, esse caso trata da análise do componente participação social na estruturação do Comitê de Bacia Hidrográfica do Rio Paraguaçu (BA). Apresentado em Pereira e Saito (2010), concluiu pela existência de uma assimetria e desproporcionalidade na representação entre regiões geográficas ou trechos de bacia hidrográfica (alto, médio e baixo curso do rio), 
evidenciando uma fragilidade tanto na legislação (no caso, a Política Nacional de Recursos Hídricos, Lei $\mathrm{n}^{\circ}$ 9.433/1997) como nos movimentos sociais que reivindicam processos participativos na gestão ambiental. Ou seja, mesmo que assegurado formalmente e assim caracterizado como um processo participativo, com representação proporcional, como é o caso dos Comitês de Bacia Hidrográfica, a participação em si pode ser mitificada e apropriada pelos setores dominantes, que no caso se utilizaram das regras vigentes de representação por setores para montar uma composição hegemônica do Alto Paraguaçu, onde justamente se localizam os grandes irrigantes, que têm interesse direto nas deliberações sobre outorga e cobrança do uso da água, tratadas no âmbito do Comitê de Bacia Hidrográfica. Ainda conforme Pereira e Saito (2010), com base nos resultados, apresentados na forma de mapa (cuja compreensão da assimetria de representação e poder salta aos olhos - uma imagem vale por mil palavras, diz um ditado), iniciou-se uma problematização dialógica no interior do Comitê de Bacia Hidrográfica do Rio Paraguaçu em torno da necessidade de rever os critérios de composição de seus membros com vistas a maior participação social. Essa discussão encaminhou-se para a aceitação de inclusão do critério de representatividade por trecho de bacia na composição do comitê, o que possibilita ampliar a reflexão sobre os processos de gestão participativa em recursos hídricos de modo geral, no que se refere à escolha de representantes por setor de usuários de água, sobretudo em bacias hidrográficas de média e grande extensão territorial. O trabalho descritivo de Pereira e Saito (2010) dialogou com outro trabalho, de caráter teórico, sobre os diferentes meios de mitificação da participação social (SANTOS; SAITO, 2006) e como, por diferentes aspectos tanto da origem como da condução do processo, os setores dominantes da sociedade se apropriam dos processos participativos para legitimar seus interesses. Portanto, desmitificar a participação social requer a análise cuidadosa dos processos individualizadamente, e, conforme tratado anteriormente, o concurso da mediação científico-tecnológica pode contribuir para introduzir maior racionalidade no exercício das práticas sociais, habermasianamente falando (HABERMAS, 1970, 1994).

Nesse caso citado, observa-se novamente um esforço para uma articulação entre teoria e prática, com o desenvolvimento de produção científica tanto de relatos descritivos como de aprofundamento teórico-metodológico resultante dessa articulação. Pode-se também reconhecer o enquadramento dessa produção na interface de diversas áreas do conhecimento: a administração (gestão participativa de bacias hidrográficas, resolução de conflitos), o direito (conceito de mediação), as geociências (cartografia temática, geoprocessamento e sensoriamento remoto, geopolítica e geografia regional), a educação de modo geral (e dentro dela, mais especificamente, a didática e o ensino de ciências, com o conceito de alfabetização científico-tecnológica), além das áreas de ecologia (e 
dentro dela a ecologia de ecossistemas), a ciência política, a economia, a agronomia, a filosofia e a sociologia.

Pode-se afirmar ainda que as articulações teoria-prática no âmbito dessa temática estão de acordo com os objetivos da Política Nacional de Educação Ambiental, particularmente no que se refere ao Artigo 5-I, que preconiza o desenvolvimento de uma compreensão integrada do meio ambiente em suas múltiplas e complexas relações, envolvendo aspectos ecológicos, psicológicos, legais, políticos, sociais, econômicos, científicos, culturais e éticos, e ao Artigo 5III, que trata do estímulo e do fortalecimento de uma consciência crítica sobre a problemática ambiental e social.

\section{Escalas geográficas}

No que se refere ao tema escalas geográficas, apresenta-se um estudo de caso que pode ser ilustrativo das pesquisas e intervenções em educação ambiental: o material didático Probio-EA, produzido para o Ministério do Meio Ambiente em 2006 e já apresentado anteriormente por mais de uma vez, só que desta vez ele é analisado de um novo ângulo. Em Saito (2009), apresentou-se a discussão sobre a importância que deve ser dada às escalas geográficas em educação ambiental, tomando-se por base esse material, cujo referencial encontra-se em Saito, Bastos e Abegg (2008). O argumento tem por base a grande aceitação da máxima ambientalista do "pensar globalmente, agir localmente", que, apesar de sua popularidade e apelo, está a exigir maior atenção do ponto de vista do desenvolvimento das estratégias para seu alcance. A razão disso é que detrás dessa máxima há uma grade dificuldade teórica referente à articulação entre escalas geográficas, que no âmbito da teoria geral de sistemas diz respeito à articulação entre níveis hierárquicos do sistema. Do ponto de vista educacional, a busca dessa máxima requer uma integração dos pares ação-reflexão, teoriaprática, fragmentação-totalização, por meio dessa mediação didaticamente produzida da análise em escala local, regional e nacional. As estratégias de manipulação dos portfólios em sala de aula propostas no livro do professor do próprio material didático e analisadas em Saito (2009) visam promover análises focadas primeiramente na escala local (par conflito socioambiental-ação positiva, tratando cada par de portfólios isoladamente), num segundo momento na escala regional (escala de bioma), procurando estimular os alunos a perceber as interações dos diversos conflitos socioambientais (problemas ou situaçõesproblema) e ações positivas (soluções existentes) de diferentes temas (biodiversidade brasileira, biomas brasileiros, espécies da fauna brasileira ameaçadas de extinção, fragmentação de ecossistemas, espécies exóticas invasoras e Unidades de Conservação da Natureza) no mesmo bioma. A sugestão de construção de uma figura (mapa conceitual) interligando temas por meio dos textos descritivos das situação de conflito socioambiental ou das respectivas 
ações positivas permite o surgimento de uma compreensão diferenciada, pela emergência de características próprias desse novo nível hierárquico de sistema. Finalmente, a proposta de num terceiro momento fazer com que os alunos reúnam e analisem os portfólios de um mesmo tema, de todos os biomas, busca obter como resultado uma compreensão por parte deles das constâncias e regularidades, bem como das particularidades regionais, que dão a visão de escala nacional (subcontinental). Esse pequeno conjunto de exercícios visa estimular cognitivamente os alunos a transitar entre escalas geográficas e diferentes níveis hierárquicos de sistema, reconhecendo e identificando a emergência de propriedades nessa transição de escalas, o que, por sua vez, permite um pensar orientado para a gestão ambiental.

Nesse caso citado, observa-se novamente um esforço para uma articulação entre teoria e prática, com o desenvolvimento de produção científica tanto do ponto de vista descritivo como do ponto de vista da busca pelo aprofundamento teórico-metodológico resultante dessa articulação. Pode-se também reconhecer o enquadramento dessa produção na interface de diversas áreas do conhecimento: a Teoria Geral de Sistemas, a geografia, a filosofia, a educação de modo geral (e dentro dela, mais especificamente, a didática e o ensino de ciências, com o conceito de alfabetização científico-tecnológica), além das áreas de ecologia (e dentro dela a ecologia de ecossistemas), a ciência política e a administração.

Pode-se afirmar ainda que as articulações teoria-prática no âmbito dessa temática estão de acordo com os princípios da Política Nacional de Educação Ambiental, particularmente no que se refere ao Artigo 4-VII-a - abordagem articulada das questões ambientais locais, regionais, nacionais e globais que nos conduz ao objetivo - e ao Artigo 5-V - o estímulo à cooperação entre as diversas regiões do País, em níveis micro e macrorregionais, com vistas à construção de uma sociedade ambientalmente equilibrada, fundada nos princípios da liberdade, igualdade, solidariedade, democracia, justiça social, responsabilidade e sustentabilidade.

\section{Teoria Geral de Sistemas e a espiral lewiniana}

No que se refere ao tema Teoria Geral de Sistemas e a espiral lewiniana, apresenta-se um estudo de caso que pode ser ilustrativo das pesquisas e intervenções em educação ambiental: o empoderamento da Comissão PróComitê de Bacia Hidrográfica do Alto Rio Maranhão (DF/GO), já apresentado anteriormente como descrito em Berlinck et al. (2003).

Neste novo enfoque, cabe a análise de como um trabalho de educação ambiental buscou interface com a pesquisa-ação (investigação-ação) e a Teoria Geral de Sistemas, contribuindo inclusive para um aprofundamento do debate teórico-metodológico no campo da pesquisa-ação (BERLINCK; SAITO, 2010). As diversas ações com a referida comissão e suas diferentes etapas foram 
estruturadas em ciclos da espiral lewiniana de planejamento - ação, observação e reflexão (Lewin, 1946) - a fim de dar um caráter formal à busca da racionalidade das práticas sociais investigadas, tendo como característica especial que essas espirais fossem aninhadas nos diferentes níveis hierárquicos, tendo a alfabetização científico-tecnológica como eixo em torno do qual a espiral se constituía, tal que para as etapas de uma espiral geral existissem espirais em níveis hierárquicos inferiores, que correspondessem a novos processos cíclicos de planejamento, ação, observação e reflexão lewinianos.

Essa incursão no campo teórico-metodológico da pesquisa-ação foi motivado pela constatação de que muitos trabalhos dessa área caíam num mero formalismo e perdiam seu caráter dialético ao assumirem a espiral lewiniana como um procedimento formal preestabelecido e desistoricizado. Isso decorre do fato de que na pesquisa-ação, enquanto concepção de pesquisa, a espiral lewiniana não deve ser tomada em absoluto como conjunto de etapas metódicas a serem seguidas, mas como uma diretriz geral que na sua implementação corresponda a diferentes etapas de aproximação ou apreensão da realidade. Assim, busca-se reforçar a proposta apresentada por Grabauska e Bastos (1998) de intensificar o debate sobre o reconhecimento da pesquisa-ação muito mais como uma concepção de pesquisa do que como um "método", como pretendeu Thiollent (1988). Na visão desses autores, com a qual aqui se concorda, a visão de Thiollent representa um reducionismo da pesquisa-ação, cujo fantasma precisa ser afastado pela via do aprofundamento do debate teórico-metodológico, visto sua popularidade entre os seguidores da pesquisa-ação.

Ao se propor uma articulação e interdependência de espirais com base na Teoria Geral de Sistemas, buscou-se dar maior consciência do sentido e potencial da espiral, bem como dos cuidados que cercam sua adoção, de forma que não a tomem de maneira absoluta e reificada, como se a simples adoção de passos sequenciais da espiral assegurasse que o trabalho tivesse o caráter de pesquisaação.

Nesse caso citado, observa-se novamente um esforço para uma articulação entre teoria e prática, com o desenvolvimento de produção científica tanto do ponto de vista descritivo como do ponto de vista da busca pelo aprofundamento teórico-metodológico resultante dessa articulação. Pode-se também reconhecer o enquadramento dessa produção na interface de diversas áreas do conhecimento: a Teoria Geral de Sistemas, a filosofia, a sociologia, a educação de modo geral, além das áreas de ecologia (e dentro dela a ecologia de ecossistemas), gestão de recursos hídricos e administração.

Pode-se afirmar ainda que as articulações teoria-prática no âmbito dessa temática estão de acordo com os objetivos da Política Nacional de Educação Ambiental, particularmente no que se refere ao Artigo 5-I - o desenvolvimento de uma compreensão integrada do meio ambiente em suas múltiplas e complexas 
relações, envolvendo aspectos ecológicos, psicológicos, legais, políticos, sociais, econômicos, científicos, culturais e éticos.

\section{Planejamento curricular, projetos coletivos e a relevância da pesquisa}

No que se refere ao tema planejamento curricular, projetos coletivos e a relevância da pesquisa, apresenta-se um estudo de caso que pode ser ilustrativo das pesquisas e intervenções em educação ambiental: um projeto de segurança alimentar desenvolvido em escola rural de Planaltina-DF, como desdobramento de projeto anterior de educação ambiental.

Esse projeto resultou no desenvolvimento de um procedimento e uma ferramenta gráfica de apoio ao planejamento educacional participativo, nos moldes da pesquisa-ação educacional proposta por Carr e Kemmis (1986), a qual é educacional quando o objeto de estudo explora a própria prática educativa do docente. No entanto, cabe chamar a atenção para o fato de que, tal como na educação ambiental, o tema segurança alimentar, na época, requeria um trabalho articulado de diversas disciplinas e respectivos professores, na perspectiva da transversalidade. E a ação empreendida e relatada em Graebner, Souza e Saito (2009) buscava envolver o conjunto dos professores de uma escola numa ação coletiva, justamente para contrapor-se às ações focadas num único professor da escola, as quais Saito (2005) já criticava por se tornarem uma ação dialógica pontual. Para este último autor, essas ações apresentam um problema de escala, com uma concentração de esforços numa única escala, a do indivíduo, em que a racionalidade da prática docente é colocada sob uma viseira, ocultando-se os conflitos interinstitucionais que representariam, na Teoria Geral de Sistemas, os "constraints" (constrangimentos, limites, restrições) do sistema (escolar). Sem essa consciência das restrições impostas pelo nível hierárquico superior, cai-se numa visão ingênua segundo a qual a melhoria das práticas docentes dependeria de uma única variável, que seria a consciência individual de suas próprias práticas e a disposição para mudá-las. Essa ingenuidade decorreria do fato de deixar-se de exercitar o que Paulo Freire (1988) chama de distanciamento da realidade, às últimas consequências. Conforme Saito (2005), acreditar que sistemas sociais apresentam independência em relação aos conceitos de hierarquia e escalas é, também, negar a universalidade dos conceitos unificadores, em que um conceito unificador de segunda ordem é reconhecido como a escala (ANGOTTI, 1991), como destacado por Bastos e Saito (2000).

Portanto, em Graebner, Souza e Saito (2009) assumiu-se a necessidade de desencadear um planejamento pedagógico e uma prática educacional coletiva e dialógica que se caracterizou como um projeto pedagógico da escola como um todo, reconhecido formalmente pela Secretaria de Educação. Os professores, reunidos, identificaram os temas e conceitos relacionados ao tema gerador central "fome", os quais estariam relacionados com a sua disciplina, e a ferramenta 
gráfica desenvolvida permitiu agrupar essas percepções individuais e disciplinares numa visão do conjunto dos professores das diferentes disciplinas, levando-os a reconhecer as interfaces e sobreposições das disciplinas para iniciar uma prática colaborativa de planejamento coletivo. Ao fazê-lo nesses moldes, buscou-se integrar as ações na escola às ações na comunidade, como ações da escola e com a escola, realizando um diagnóstico das práticas alimentares e do estado nutricional dos alunos e utilizando os resultados desse diagnóstico para retroalimentar o planejamento das práticas pedagógicas na escola sobre o tema fome e segurança alimentar. Conseguiu-se assim promover maior racionalidade das práticas pedagógicas docentes e das práticas sociais na comunidade pela valorização dos frutos do Cerrado, entre outros meios, além de incentivar a prática de cultivo de hortas domiciliares. Por sinal, esse aspecto do cultivo de hortaliças pelos pais dos alunos foi motivo de conflitos sociais, visto que esses pais eram caseiros em chácaras e seus proprietários eram resistentes a essas práticas por acharem que isso consumia água e energia elétrica, o que exigiu uma mediação no interior justamente da Comissão Pró-Comitê de Bacia Hidrográfica em que a Universidade de Brasília também atuava (vide subseção anterior) para esclarecer que a sustentabilidade que esses membros (e também proprietários) defendiam nesse fórum passava pela segurança alimentar da comunidade. Esse enfrentamento fazia parte de um compromisso ético da pesquisa com os pesquisados, conforme defendido por Smith (1996). Dessa forma, no saldo global, o projeto permitiu a promoção do empowerment (FRIEDMANN, 1992; SAITO, 2001) dos diversos atores sociais envolvidos.

Também nesse caso citado reconhece-se um esforço para uma articulação entre teoria e prática, com o desenvolvimento de produção científica tanto do ponto de vista descritivo como do ponto de vista da busca pelo aprofundamento teórico-metodológico resultante dessa articulação. Pode-se também vislumbrar o enquadramento dessa produção na interface de diversas áreas do conhecimento: a Teoria Geral de Sistemas, a filosofia, a sociologia, a educação de modo geral (e dentro dela, mais especificamente, o currículo, o planejamento educacional, a transversalidade), além das áreas de ecologia (e dentro dela a ecologia aplicada e a ecologia de ecossistemas), gestão de recursos hídricos, nutrição humana, saúde pública e administração.

Pode-se afirmar ainda que as articulações teoria-prática no âmbito dessa temática estão de acordo com os objetivos da Política Nacional de Educação Ambiental, particularmente no que se refere ao Artigo 5-I - o desenvolvimento de uma compreensão integrada do meio ambiente em suas múltiplas e complexas relações, envolvendo aspectos ecológicos, psicológicos, legais, políticos, sociais, econômicos, científicos, culturais e éticos, tomando por base o princípio disposto no Artigo 4-IV: a vinculação entre a ética, a educação, o trabalho e as práticas sociais. 


\section{As instalações físicas da escola para a EA}

No que se refere ao tema as instalações físicas da escola para a $E A$, apresenta-se um estudo de caso que pode ser ilustrativo das pesquisas e intervenções em educação ambiental: uma pesquisa realizada em Natal-RN sobre as instalações físicas das creches. Esse trabalho, conduzido por Elali (2003), se ocupou de avaliar o ambiente físico de estabelecimentos educativos para educação infantil, sua ocupação e a percepção dos usuários. A pesquisa envolveu vistoria técnica (levantamento e documentação arquitetônica), observação comportamental (traços e mapeamento), questionários, entrevistas e desenhos temáticos, segundo a autora. O que torna esse estudo interessante e o motivo de ter sido relacionado para tratar da pesquisa em educação ambiental em diferentes áreas do conhecimento é o fato de ela evitar discutir o conteúdo disciplinar ministrado pelos professores ou sua formação, optando por discutir o que o ambiente físico de nossas escolas está atualmente ensinando a seus alunos, sobretudo no que se refere ao contato com a natureza. Em outras palavras, tentou-se compreender que lições de "contato com a natureza" estariam sendo não verbalmente ensinadas às crianças nas escolas de educação infantil. Elali (2003) se apoia em Fedrizzi (2002, p. 224), que conclui que, "de modo geral, os pátios escolares não seguem um projeto definido, sendo, na maioria das vezes, considerados apenas como um local onde as crianças ficam quando não estão em sala de aula". Segundo Elali (2003), na maioria das escolas visitadas a área construída (edificação) ocupa entre 50\% e 75\% do lote em que estão implantadas, e, embora tais percentuais estejam em consonância com o Plano Diretor de Natal/PDN, que determina uma ocupação máxima de $80 \%$ do terreno, essa taxa de ocupação conflita tanto com os critérios para a obtenção de autorização/reconhecimento dos estabelecimentos de ensino do Conselho Estadual de Educação, que indica uma ocupação máxima de $1 / 3$ da área existente (ou, no mínimo, uma área livre de $3 \mathrm{~m}^{2} /$ aluno), quanto com as normas do FundEscola, que sugere o uso de apenas $50 \%$ do lote.

No entanto, o que é interessante no trabalho de Elali (2003) é a análise feita de que cerca de $20 \%$ dos estabelecimentos, apesar de manterem áreas livres, não dispunham de qualquer árvore ou arbusto de maior porte na área interna do lote (porque poderiam representar riscos para as crianças ao subirem nelas), restringindo a presença do verde a alguns vasos com plantas. Nas áreas não edificadas dos estabelecimentos (que corresponderiam a pátios), além da ausência de árvores, foi comum encontrar o revestimento das áreas livres com cerâmica e/ou pedra ou a execução de piso cimentado, algumas vezes pintado na cor verde, simulando grama, com diferentes alegações de motivos, entre eles a facilidade de manutenção da limpeza. As janelas, de dimensões insuficientes tanto para a ventilação quanto para a iluminação das salas de aula, não estavam posicionadas de modo a induzir a ventilação-cruzada entre os cômodos, e seu 
peitoril geralmente era alto demais para a estatura das crianças, propositalmente definidos nessa altura para não permitir que as crianças visualizem a área externa e se "distraíssem" da aula olhando a chuva, o sol ou as borboletas. Curiosamente, essas mesmas salas apresentavam pinturas com temas sobre a natureza decorando as paredes, sugerindo uma necessidade de aproximação de contato com o meio ambiente, porém controlada. A investigação feita nessas mesmas escolas com as crianças evidenciou a necessidade de uma interação mais ativa e constante com o meio natural, como sentar na areia, pegar em pequenos animais, molhar-se, a qual surge enfaticamente no discurso e nos desenhos infantis, segundo Elali (2003). A autora constatou uma diferença entre pontos de vista de crianças e adultos: enquanto as primeiras valorizam as áreas livres e o contato com a natureza, os segundos preocupam-se com aspectos estéticos e com a sala de aula em si. Finalmente, conclui que para os adultos, sobretudo os pais, embora indiquem a necessidade de a natureza estar mais presente na escola, em sintonia com a valorização da retórica ambientalista, condicionam essa presença a um controle relativamente severo, ou seja, essa presença é "controlada/domesticada".

Do ponto de vista do planejamento do espaço escolar, o que esse estudo traz de rico é o fato de, embora esse espaço devesse estar totalmente voltado para o atendimento das necessidades infantis, essas necessidades serem ignoradas ou transfiguradas, passando o espaço a ser diretamente controlado e socialmente construído pelos adultos.

Nesse caso citado, observa-se novamente um esforço para uma articulação entre teoria e prática e uma busca do enquadramento dessa produção na interface de diversas áreas do conhecimento, como a engenharia, a arquitetura, a psicologia, e a educação de modo geral (e a educação infantil e a administração escolar, além da gestão escolar e a interação escola-comunidade), além das áreas de ecologia e saúde pública. O que chama a atenção nesse trabalho é justamente a mudança de foco: na maioria das vezes, em termos de educação ambiental, nos preocupamos com o interior da sala de aula e o trabalho docente (muitas vezes carregado de uma preocupação conteudista), e a autora chama a atenção para a influência do espaço físico e sua concepção, indicando a necessidade de interação dos educadores, engenheiros, psicólogos, arquitetos, e biólogos para o planejamento da construção da escola como precondição para o planejamento das atividades de educação ambiental no âmbito da educação infantil.

Pode-se afirmar ainda que as articulações teoria-prática no âmbito dessa temática estão de acordo com os objetivos da Política Nacional de Educação Ambiental, particularmente no que se refere ao Artigo 5-I - o desenvolvimento de uma compreensão integrada do meio ambiente em suas múltiplas e complexas relações, envolvendo aspectos ecológicos, psicológicos, legais, políticos, sociais, econômicos, científicos, culturais e éticos - e ao Artigo5-VI - o fomento e o fortalecimento da integração com a ciência e a tecnologia, tendo como princípio 
o Artigo 4-VI: a permanente avaliação crítica do processo educativo, que nesse caso se inicia antes mesmo da construção do espaço físico escolar.

\section{Conhecimento e valores}

No que se refere ao tema conbecimento e valores, apresenta-se um estudo de caso que pode ser ilustrativo das pesquisas e intervenções em educação ambiental: os resíduos de pesquisa numa reserva ecológica do Distrito Federal. Nesse trabalho, que ainda é inédito e está em vias de publicação, sob o título "Does a Baconian vision of nature dominate among researchers in Ecology? A case study in the Ecological Reserve of IBGE in Central Brazil' (SAITO; GOMES; ALMEIDA, sem data), os autores partiram dos dados de levantamento de resíduos deixados para trás por pesquisadores após a conclusão das pesquisas. Diante da grande quantidade de resíduos encontrados na Reserva Ecológica do IBGE (RECOR), a questão posta é: por que esses pesquisadores, cuja área do conhecimento e os objetivos de atuação profissional vinculam-se à temática e ao interesse na conservação da natureza, produziram os resíduos descritos? Uma vez que todos os pesquisadores assinaram um termo de compromisso para a realização de pesquisas na RECOR com a concordância da retirada de todo o material do campo ao final da pesquisa, de forma a garantir a integridade do local e a possibilidade de utilização dos resultados para o manejo da própria área, esse abandono de material nos locais de estudo não pode simplesmente ser atribuído à falta de orientação. Também não pode ser atribuído ao descumprimento por terceiros a quem os pesquisadores designaram a retirada do material, visto que para tanto os pesquisadores deveriam encaminhar um cadastro de ingresso à RECOR desse contratado na área. Após reflexões em torno do problema e a sua discussão em disciplina com alunos de pós-graduação, na qual surgiram inclusive posicionamentos enfáticos de que não retornariam à área de pesquisa para a retirada dos resíduos por ser um "esforço energético" improdutivo, terminou-se por recorrer a um referencial teórico obtido em Sheldrake (1993) que ajuda no entendimento desse comportamento. Segundo esse autor, haveria uma herança de Francis Bacon e sua visão de domínio da natureza pelo homem que estaria na raiz da constituição da ciência moderna. Nesse caso, a natureza estaria servindo de mero objeto para a satisfação de seu interesse pessoal de curiosidade e ascensão social via a obtenção de títulos de mestrado ou doutorado por meio das pesquisas (paradigma da dominação e usufruto), sem que isso desenvolva no pesquisador e seu orientador um compromisso profundo nos termos da deep ecology com a natureza; muito pelo contrário, no discurso do aluno de pósgraduação citado configura-se uma retórica letrada de objetivação e desapego afetivo da natureza, além do distanciamento da reflexão sobre a ética e a responsabilidade da pesquisa científica (paradigma da fragmentação). 
Esse caso ilustra uma situação nova e perturbadora na área da educação ambiental, pois em geral se atribuiu à falta de conhecimento sobre os processos da natureza a origem da falta de compromisso e cuidado com o meio ambiente, assumindo a educação ambiental para si a tarefa de educar, informar e, a partir disso, transformar as atitudes das pessoas. Nessa linha de raciocínio, o aumento da escolarização formal, a melhoria da qualidade do ensino e a ampliação do acesso à cultura sempre fizeram parte da pauta de compromissos históricos dos educadores ambientais, conjuntamente com outros setores da sociedade. No entanto, nesse caso citado, têm-se pessoas que constituem a minoria altamente privilegiada da sociedade, com alto nível de escolarização (ensino superior mais pós-graduação). Mais ainda, não se trata de escolarização em qualquer área do conhecimento, mas uma escolarização específica na área ambiental, e exercício profissional (no caso dos pesquisadores doutores, pesquisadores seniores) na área do meio ambiente. Portanto, sugere-se que nesse caso específico não é o conhecimento na área ambiental que gera ou mobiliza os compromissos mais profundos com a conservação da natureza, o que passa a exigir da área da educação ambiental reflexões sobre a importância de desenvolver questionamentos acerca de valores e ética profissional, com apoio na filosofia, nos cursos de formação profissional, e as reflexões feitas por autores como Sheldrake (1993) podem contribuir nesse sentido.

Também nesse caso citado reconhece-se um esforço para uma articulação entre teoria e prática, com o desenvolvimento de produção científica tanto do ponto de vista descritivo como do ponto de vista da busca pelo aprofundamento teórico-metodológico resultante dessa articulação. Esse estudo de caso pode ser enquadrado na interface de diversas áreas do conhecimento: a filosofia, a sociologia, a psicologia, a espiritualidade, além das áreas de ecologia (e dentro dela a ecologia aplicada e a ecologia de ecossistemas) e gestão ambiental.

Pode-se afirmar ainda que essas articulações teoria-prática no âmbito dessa temática estão de acordo com os objetivos da Política Nacional de Educação Ambiental, particularmente no que se refere ao Artigo 5-I - o desenvolvimento de uma compreensão integrada do meio ambiente em suas múltiplas e complexas relações, envolvendo aspectos ecológicos, psicológicos, legais, políticos, sociais, econômicos, científicos, culturais e éticos, tomando por base o princípio disposto no Artigo 4-IV: a vinculação entre a ética, a educação, o trabalho e as práticas sociais.

\section{Considerações finais}

É importante sustentar que se deve ter como referência da definição de educação ambiental o disposto na Política Nacional de Educação Ambiental, Art. 1: "Entendem-se por educação ambiental os processos por meio dos quais o indivíduo e a coletividade constroem valores sociais, conhecimentos, habilidades, 
atitudes e competências voltadas para a conservação do meio ambiente, bem de uso comum do povo, essencial à sadia qualidade de vida e sua sustentabilidade".

Além do atendimento de princípios e objetivos da Política Nacional de Educação Ambiental, caso a caso tratado nas subseções anteriores, cabe assinalar que nos diversos temas é possível afirmar que os vários aspectos da formação do indivíduo e coletividade por meio da educação ambiental são contemplados conforme disposto no Artigo 1 da Lei no 9.795/1999: na abordagem dialógicoproblematizadora e conflitos socioambientais pode-se visualizar mais destacadamente o aspecto da construção do conhecimento, atitudes e valores sociais; na mediação científico-tecnológica destaca-se o aspecto da construção do conhecimento, competências e habilidades; no mito da democracia e participação aponta-se a presença da construção do conhecimento, atitudes e valores sociais; nas escalas geográficas indica-se a presença da construção de conhecimento, competências e habilidades; na Teoria Geral de Sistemas e espiral lewiniana evidencia-se a construção de habilidades e competências; no planejamento curricular, projetos coletivos e relevância da pesquisa apresenta-se a realização da construção de conhecimentos, atitudes, habilidades, competências e valores; ao tratar-se das instalações físicas da escola para a EA, observa-se a construção de conhecimentos e competências; e, finalmente, ao tratar-se dos conhecimento e valores, mostra-se que valores e atitudes são construídos.

Em cada caso, também, buscou-se atender ao disposto no Art. 3 da Lei ${ }^{\circ}$ 9.795/1999, que dispõe o seguinte: "Incumbe-se [...] VI - à sociedade como um todo, manter atenção permanente à formação de valores, atitudes e habilidades que propiciem a atuação individual e coletiva voltada para a prevenção, a identificação e a solução de problemas ambientais". Ou seja, as ações de educação ambiental destinam-se a promover uma atitude pró-ativa, de atuação individual e coletiva voltada para a melhoria da qualidade ambiental e sua sustentabilidade, não se restringindo a uma mera aquisição de conhecimento de forma contemplativa, satisfazendo o ego pessoal pelo aumento do saber.

Finalmente, não cabe aqui reescrever as diversas interfaces de áreas do conhecimento envolvidas, que já foram repetidamente apontadas em cada subseção; no entanto, cabe reafirmar que se deve buscar explicitar essas interfaces a fim de tomar consciência dos objetivos e etapas da ação educativa em desenvolvimento por meio da educação ambiental, de tal modo que enquanto educadores ambientais possamos desenvolver, em nós mesmos, uma consciência maior do nosso saber-fazer, empoderando-nos também ao buscar maior racionalidade das nossas práticas educadoras. Essa busca da racionalidade passa também pela integração teoria-prática, que pode contribuir para o aumento qualitativo de nossa produção científica na área e fazer com que os lamentos repetitivos de que a produção científica tem predomínio de casos meramente descritivos se torne coisa do passado. Desse modo, poderemos, sim, gerar produção científica de cunho descritivo e relatorial com o saber-fazer detalhado e 
justificado. Além disso, com base nesses relatos descritivos, poderemos aprofundar os debates e reflexões no campo teórico-metodológico das interfaces das diferentes áreas do conhecimento que se entrelaçam com a educação ambiental.

\section{Referências}

ANGOTTI, José André Peres. Fragmentos e Totalidades no Ensino de Ciências. 1991. Tese (Doutorado em Educação) - Faculdade de Educação, Universidade de São Paulo, São Paulo, 1991.

BASTOS, Fábio da Purificação de; SAITO, Carlos Hiroo. Abordagem energética na educação ambiental. ADVIR, Rio de Janeiro, n. 13, p. 11-19, 2000.

BAZIN, Maurice Jacques. O cientista como alfabetizador técnico. In: ANDERSON, Sam; BAZIN, Maurice Jacques (Org.). Ciência e In/Dependência. Lisboa: Livros Horizonte, 1977. p. 94-98. (v. 2).

BERLINCK, Christian Niel; SAITO, Carlos Hiroo. Action Research for Emancipation Informed by Habermas and Hierarchy of Systems: Case Study on Environmental Education and Management of Water Resources in Brazil. Systemic Practice and Action Research, v. 23, n. 2, p. 143-156, 2010.

BERLINCK, Christian Niel; SANTOS, Irenilda Ângela; SILVA, Carolina Montijo da; TAVOLUCCI, Alexandre Benso Lima; STEINKE, Valdir Adilson; STEINKE, Ercilia Torres; MELO, Vitória Régia Martins; ALMEIDA, Fernando José de; SILVA, Maria Irenilda da Costa; GOLEBIOWSK, Slawomir Mauricio; SAITO, Carlos Hiroo. Educação Ambiental como Círculo de Cultura Freireano por meio de investigação-ação: estudo de caso sobre instrumentalização de comitês de bacia hidrográfica. Rev. Eletr. Mestr. Educação Ambiental, v..10, p. 89-103, jan./jun. 2003.

BOAL, Augusto. Teatro do Oprimido e outras poéticas políticas. Rio de Janeiro: Civilização Brasileira, 1975.

CARR, Wilfred; KEMMIS, Stephen. Becoming critical: education, knowledge and action research. Brighton, UK: The Falmer Press, 1986.

ELALI, G.leice Azambuja. O ambiente da escola - o ambiente na escola: uma discussão sobre a relação escola-natureza em educação infantil. Estud. Psicol., Natal, v. 8, n. 2, p. 309-319, 2003.

FEDRIZZI, Beatriz Maria. Organização em pátios escolares grandes e pequenos. In: Del_Rio, Vicente; DUARTE, Cristiane Rose; RHEINGANTZ, Paulo Afonso (Org.). Projeto do lugar: colaboração entre Psicologia, Arquitetura e Urbanismo. Rio de Janeiro: Contra Capa Livraria/PROARQ, 2002. p. 221-230.

FREIRE, Paulo. Extensão ou Comunicação? Rio de Janeiro: Paz e Terra, 1977. 
. Pedagogia do Oprimido. Rio de Janeiro: Paz e Terra, 1988.

FRIEDMANN, John. Empowerment the politics of the alternative development. Cambridge: Blackwell Publishers, 1992.

GRABAUSKA, Clainton José; BASTOS, Fábio da Purificação de. Investigação-ação educacional: possibilidades críticas e emancipatórias na prática educativa. Heuresis: Revista eletrónica de investigación curricular y educativa, Cadiz, Espanha, v. 1, n. 2, 1998. Disponível em: <http://www2.uca.es/HEURESIS/heuresis98/v1n2-2.html>. Acesso em: 20 out. 2010.

GRAEBNER, Ivete Teresinha; SOUZA, Elizabeth Maria Talá de; SAITO, Carlos Hiroo. Action-research and Food and Nutrition Security: A school experience mediated by conceptual graphic representation tool. International Journal of Science Education, v. 31, n. 6, p. $809-827,2009$.

HABERMAS, Jürgen. Toward a rational society. Student protest, science and politics. Scientization of politics and public opinion. Boston: Beacon Press, 1970.

. Técnica e ciência como "ideologia". Lisboa: Edições 70, 1994.

KAMKWAMBA, William; MEALER, Bryan. O menino que descobriu o vento. Rio de Janeiro: Objetiva, 2011.

LEWIN, Kurt. Action research and minority problems. Journal of Social Issues, v. 2, p. 3446, 1946.

PEREIRA, Maria do Carmo Nunes; SAITO, Carlos Hiroo. A geopolítica e as ilusões sobre a democracia e participação social na gestão de recursos hídricos: o Comitê de Bacia Hidrográfica do rio Paraguaçu (BA) como estudo de caso. In: ENCONTRO DA ANPPAS, 5., 2010, Florianópolis, SC. Anais... Florianópolis: ANPPAS, 2010. p. 1-13.

SAITO, Carlos Hiroo. "Cocô na praia, não!” Educação ambiental e lutas populares. Revista Ambiente \& Educação, v. 4, n. 1, p. 45-57, 1999.

- Por que investigação-ação, empowerment e as idéias de Paulo Freire se integram?. In: MION, Rejane Aurora; SAITO, Carlos Hiroo (Org.). Investigação-Ação: Mudando o Trabalho de Formar Professores. Ponta Grossa, PR: Gráfica Planeta, 2001. p. 126-135.

- Política Nacional de Educação e Construção da Cidadania: Desafios Contemporâneos. In: Ruscheinsky, Aloísio (Org.) Educação Ambiental: Abordagens Múltiplas. Porto Alegre: Artmed, 2002. p. 47-60.

. Contrapontos a uma análise das práticas em investigação-ação. In: ESCOLA DE INVESTIGAÇÃO-AÇÃO, 9., 2005, Santa Maria, RS. Atas... Santa Maria: UFSM, 2005. p.1-14.

- Educação Ambiental no Brasil e a crise socioambiental mundial. Espaço em Revista, Catalão, GO, v. 11, n. 2, p. 1-14, 2009. Disponível em: $<$ http://www.catalao.ufg.br/geografia/iisea/Anais eletrônicos

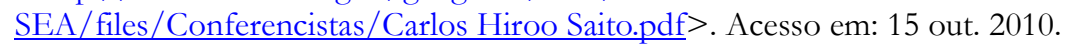

SAITO, Carlos Hiroo; SANTIAGO, Sandra H. M. Tema Gerador e Dialogicidade: os riscos de uma filiação ao liberalismo em leituras diferenciadas de Paulo Freire. Revista Estudos Leopoldenses, v .2, n. 3, p.71-80, jul./dez. 1998. 
SAITO, Carlos Hiroo; BASTOS, Fábio da Purificação de; ABEGG, Ilse. Teorias-guia educacionais da produção dos materiais didáticos para a transversalidade curricular do meio ambiente do MMA. Revista Iberoamericana de Educación [online], v. 45, p. 1-10, 2008. Disponível em: <http://www.rieoei.org/expe/1953Saito.pdf>. Acesso em: 20 out. 2010. SAITO, Carlos Hiroo; RUSCHEINSKY, Aloísio; BASTOS, Fábio da Purificação de; NUNES, Jacy Bandeira Almeida; SILVA, Luciano Fernandes; CARVALHO, Luiz Marcelo de. Conflitos Socioambientais, Educação Ambiental e Participação Social na Gestão Ambiental. Sustentabilidade em Debate, Brasília, v. 2, n. 1, p. 121-138, 2011. Disponível em: <http://www.red.unb.br/index.php/sust/article/view/3910/3321>. Acesso em: 08 fev. 2012.

SAITO, Carlos Hiroo; GOMES, Mariana R.; ALMEIDA, Luzia E. Does a Baconian vision of nature dominate among researchers in Ecology? A case study in the Ecological Reserve of IBGE in Central Brazil. Human Ecology, v. 39, n. 6, p. 835-839.

SANTOS, Irenilda Ângela dos; SAITO, Carlos Hiroo. A mitificação da participação social na Política Nacional de Recursos Hídricos - gênese, motivação e inclusão social. Geosul, v. 21, n. 42, p. 7-27, 2006.

SANTOS, Irenilda ângela dos; BERLINCK, Christian Niel; ARAUJO, Simone Cristina de Santana; STEINKE, Ercilia Torres; STEINKE, Valdir Adilson; PIANTA, Taissa Ferreira; GRAEBNER, Ivete Teresinha; SAITO, Carlos Hiroo. The Centrality of the mediation concept in the participatory management of water. Canadian Journal of Environmental Education, Ontario, Canadá, v. 10, n.1, p. 180-194, 2005. Available from: <http://cjee.lakeheadu.ca/index.php/cjee/article/view/186/31>. Cited: 10 Dec. 2010.

SHELDRAKE, Rupert. O renascimento da natureza: o reflorescimento da Ciência e de Deus. São Paulo: Cultrix, 1993.

SMITH, Bob. Addressing the delusion of relevance: struggles in connecting educational research and social justice. Educational Action Research, v. 4, n. 1, p. 73-91, 1996.

THIOLLENT, Michel. Metodologia da pesquisa-ação. São Paulo: Cortez, 1986.

VIEGAS, Chandra Wood; ALMEIDA, G.láucia Ferreira de; PINTO JÚNIOR, Aymoré Vaz; SCHUMACHER, Heloisa Cristina; MARTINS, Carolina Cristina Barros e; CORREIA, Cleiton de Souza; DOURADO, Elisabeth Brandão; SIQUEIRA, Leandro de Castro; BARROS, Elisabeth Ramos; SAITO, Carlos Hiroo. Educação ambiental para a redução da produção de lixo:ação dialógica e histórias em quadrinhos. Revista Brasileira de Educação Ambiental, v. 2, p. 105-114, 2007.

Artigo recebido em 10/10/2012

Artigo aprovado em 12/12/2012 